\title{
Ultrapure water in haemodialysis: a step towards better quality in Lebanon
}

Mabel Aoun, ${ }^{1}$ Jihad Makkouk ${ }^{2}$ and Walid Ammar ${ }^{3}$

${ }^{1}$ Nephrology Department. Saint-Joseph University, Beirut, Lebanon. ${ }^{2}$ Lebanese Ministry of Public Health. ${ }^{3}$ General Director, Lebanese Ministry of Public Health Beirut, Lebanon. (Correspondence to: Mabel Aoun: aounmabel@yahoo.fr).

\begin{abstract}
Globally the nephrology community is witnessing an increased use of high-flux membranes and ultrapure water in haemodialysis (HD) units, and in low-and middle-income countries, data are lacking regarding HD water quality. In Lebanon the Ministry of Public Health released a decree calling for a progressive change in the HD water treatment system in order to implement ultrapure water in all dialysis facilities. This article reports on the problems previously encountered regarding water quality in Lebanon. It exposes the recent changes in standards as recommended by the government, especially the mandatory three sessions per week and ultrapure water. In addition, it analyses the cost-effectiveness of ultrapure water implementation in a low/middle-income country and demonstrates that the cost is lower than in high-income countries. Finally, this article summarizes the obstacles met and suggests a practical approach to maintain this high level of water treatment quality.
\end{abstract}

Keywords: haemodialysis, ultrapure water, public health reform, developing countries

Citation: Aoun M; Makkouk J; Ammar W. Ultrapure water in haemodialysis: a step towards better quality in Lebanon. East Mediterr Health J. 2019;25(2):134-141. https://doi.org/10.26719/emhj.18.032

Received: 28/02/17; accepted: 03/10/17

Copyright (c) World Health Organization (WHO) 2019. Some rights reserved. This work is available under the CC BY-NC-SA 3.o IGO license (https:// creativecommons.org/licenses/by-nc-sa/3.o/igo).

\section{Introduction}

Patients undergoing chronic haemodialysis (HD) three times per week, four hours each, are exposed to a high volume of water between 360 and 576 litres weekly depending on their dialysate blood flow $(500$ to $800 \mathrm{~mL} /$ $\mathrm{min})$. Therefore contamination of this water by microorganisms or toxic chemicals could be very harmful to the patient's health, and it becomes mandatory to achieve the highest level of purity of water coming into close contact with a patient's blood. Worldwide, the nephrology community is witnessing an increased use of high-flux membranes with or without haemodialfiltration (HDF) and consequently ultrapure water becomes a must with those treatment modalities (1). Many nephrologists, especially in Europe and Japan, believe that the ultimate goal to improve patient outcomes is the eventual global transition to the use of ultrapure fluids $(2,3)$. In low- and middle-income countries, there are several published papers comparing the cost of different dialysis modalities, but data are lacking regarding their respective water quality $(4,5)$.

Lebanon is an upper middle-income country with a total population estimated at 4.5 million in 2014 (6). The regulations concerning the HD water treatment system in Lebanon and agreement between each dialysis centre and the Lebanese Ministry of Public Health (MoPH), have not been amended for more than 20 years. On the contrary, worldwide guidelines concerning water purification for dialysis have evolved and have been continuously updated by the International Standards Organization (ISO) (7-10). Moreover, two problems emerged lately. First, the persistent inquiry by the Lebanese hospitals' union to increase dialysis reimbursement fees by the
$\mathrm{MoPH}$; and second, the use of high-flux membranes in some Lebanese centres despite the absence of ultrapure water and endotoxins measurement. Knowing that endotoxins, when entering the patient's blood, can lead to pyrogenic reactions, septicemia and even death $(8,11)$, improving water purity is a requisite.

Consequently, under those circumstances and in collaboration with the Lebanese Society of Nephrology and Hypertension, the Lebanese MoPH released in September 2014 a new decree (number 1/1690) calling for a progressive change in the HD water treatment system over a one-year period in order to implement ultrapure water in all dialysis facilities. Simultaneously, the $\mathrm{MoPH}$ raised the reimbursement of HD. This decree provided time for hospitals, institutions and dialysis providers to understand and assimilate the new standards in order to start adopting the new water treatment system and develop strategies to ensure long-term compliance. This report aims to expose the problems previously encountered regarding the water quality lately. It will also review the recent changes and rationale of the standards as recommended by the MoPH. It will evaluate as well the cost-effectiveness of ultrapure water implementation in a low/middle-income country, the obstacles met and the lessons learned to maintain this new water treatment system.

\section{Dialysis in Lebanon}

At the beginning of 2015, 70 dialysis facilities were well established in Lebanon, providing HD to 3350 Lebanese patients approximately. Among the $70 \mathrm{HD}$ centres, 59 were located in private hospitals and 11 in public hospi- 
tals. Around 150 patients were undergoing peritoneal dialysis (PD). Table 1 summarizes the distribution of the prevalent and incident rates of $\mathrm{HD}$ and $\mathrm{PD}$ patients as well of nephrologists. The incident and prevalent rates of ESRD in Lebanon are similar to many countries worldwide (12). However, there is a relatively low proportion of ESRD patients per nephrologist (27 patients).

The opening of a new dialysis centre requires prior approval of the MoPH. The latter imposes quality measures and does not allow or covers HD outside hospitals, making home HD very difficult. Each HD session cost is reimbursed totally by the MoPH, the National Social Security Fund (NSSF), the Army, the Internal Security Forces (ISF) or the Civil Servants Cooperative (CSC). Private insurances do not cover dialysis therapy in Lebanon and insured patients will be automatically covered by $\mathrm{MoPH}$ when they need dialysis.

The MoPH was covering in 2015 the dialysis of approximately 1600 patients per month, half of the Lebanese HD population. The average number of sessions of hemodialysis per patient per month was 11.5, since many centres in the south of Lebanon had a small proportion of patients undergoing dialysis only twice per week. Therefore, the total number of HD sessions reimbursed by the MoPH was around 221000 annually.

\section{Problems previously encountered regarding water quality in Lebanon: data collection 2012-2014.}

As previously mentioned, the MoPH imposes quality measures that dialysis centres should follow and report monthly. Each centre sends to the MoPH on a monthly basis the type of filters used, the results of the dialysis fluid analysis for chemical contaminants, and the water culture. Endotoxin level was not mentioned in the previous agreement.

To examine this, data were retrospectively collected from each dialysis centre's report at the MoPH between June 2012 and June 2014. The results of 67 centres were as follows: concerning the culture results, one centre had 20000 CFUs for two consecutive months, two centres had repetitive pseudomonas, 26 centres reported culture negative, and 26 centres reported o CFUs. Twelve 12 centres never sent any culture result.

Concerning the chemical analysis: only two centres sent a complete chemical analysis. Forty-four centres sent calcium and/or sodium and/or chloride tested in the local laboratory, and the majority of them were above the maximum level allowed. Forty-two centres sent the calcium level. Calcium was $>2 \mathrm{mg} / \mathrm{l}(>0.2 \mathrm{mg} / \mathrm{dL})$ in 15 reports (5-58 $\mathrm{mg} / \mathrm{dL})$.

Only eight centres provided the MoPH with the Total Dissolved Solids (TDS) measurement result: five of the eight had a TDS $\geq 10 \mathrm{ppm}$ (TDS reflects the performance of the reverse osmosis unit and should be $<10 \mathrm{ppm}$ ). Not a single report was signed by the nephrologist.

Four centres were using high-flux membranes. One centre was equipped with the ultrapure water, but none of these centres performed the endotoxin level monitoring. No reports were available about the symptomatology of patients in those centres that had bacterial and chemical contamination of the dialysis fluid.

The only plausible explanation of those results is the lack of involvement of the nephrologists in the monitoring of the water quality. Therefore, it is imperative that nephrologists realize they must have a good knowledge of their facility's water treatment system to ensure that purified water used in dialysis meets the standards for quality as recommended by ISO standards (13).

\section{New recommendations by MoPH: ultrapure water}

As a response to the inadequate water quality in several $\mathrm{HD}$ facilities, the MoPH decided to update the recommendations regarding water treatment system for HD, and follow very closely the execution of this policy and the regular monitoring of the water analysis. The decree released emphasized the use of ultrapure water in all Lebanese dialysis facilities. Ultrapure water is characterized by a bacteria level below $0.1 \mathrm{CFU} / \mathrm{mL}$ and endotoxin level below $0.03 \mathrm{EU} / \mathrm{mL}$ as recommended by the ISO (10).

\section{The water treatment system}

In order to secure ultrapure water, the $\mathrm{MoPH}$ made a proposal for the water treatment system based on ISO 26722:2014 (8) and made up of the following: pretreatment, reverse osmosis (RO), endotoxin-retentive filter and distribution to the machines.

Pretreatment cascade is similar to the older one and consists of preliminary filtration of the municipal drinking water with microfilters and sediment filters, softening, and filtration through activated carbon. The water softener exchanges $\mathrm{Na}+$ ions for $\mathrm{Ca}++$ and $\mathrm{Mg}++$

\begin{tabular}{lccc}
\hline $\begin{array}{l}\text { Table } 1 \text { Incident and prevalent estimated rates of ESRD patients and nephrologists in Lebanon in 2015 per million population } \\
\text { (pmp) }\end{array}$ & $\begin{array}{c}\text { Estimated absolute number } \\
\text { in 2015 }\end{array}$ & $\begin{array}{c}\text { Average incidence between } \\
\text { 2014 and 2015 (pmp) }\end{array}$ & Prevalence (pmp) \\
& 132 & 1.5 & 29 \\
Nephrologists & 3350 & 187 & 744 \\
HD patients & 150 & 4 & 33 \\
PD patients & 3500 & 191 & 777 \\
ESRD patients on dialysis & \begin{tabular}{ll} 
(20) \\
\hline
\end{tabular}
\end{tabular}


as well as for other cations. Activated carbon removes chlorine and chloramine that are not removed by RO; one or two carbon beds are installed depending on the level of chloramine previously used to disinfect the municipal drinking water.

A double Reverse Osmosis (RO) unit (two ROs in series) is recommended, and endotoxin-retentive filter at locations downstream of RO is also recommended. The water distribution system is the piping system and configured in a loop with direct feed of the purified water from the RO pump to the dialysis unit and back to the RO. Chemical or heat disinfection of the water distribution system is recommended. Heat-resistant materials should be used in piping systems to be disinfected by hot water. Storage tanks should be avoided. One pyrogen filter on each dialysis machine is mandatory (two are necessary for online HDF).

\section{Bacterial and chemical contaminants monitor- ing}

Endotoxin, water culture, TDS and total chlorine should be sent monthly to the MoPH and a total chemical analysis once a year. It is recommended also to follow daily the TDS and total chlorine. The maximum levels allowed for toxic chemicals, fluid electrolytes and microbiological contaminants in dialysis water as recommended by the ISO (10) are summarized in Tables 2 and 3.

Nephrologists should not confuse chlorine with chloramine. Total chlorine is the sum of free and combined chlorine. Chlorine can exist in water as dissolved molecular chlorine, hypochlorous acid, and/or hypochlorite ion (free chlorine) or in chemically combined forms (combined chlorine). Where chloramine is used to disinfect water supplies it is usually the principal component of combined chlorine. There is no direct test for measuring combined chlorine, but it can be measured indirectly by measuring both total and free chlorine and calculating the difference.

Suggested sites of sampling for toxic chemicals, post$\mathrm{RO}$ and for endotoxin test are the first and end point of the distribution loop. The presence of endotoxin is determined using the limulus amoebocyte lysate (LAL) method and is based on using a gel-clot or turbidimetric, colorimetric or fluorescent methods. The most sensitive is the kinetic chromogenic assay detecting very low concentrations of endotoxins. However, it is noteworthy to remember that extremely small fragments of lipopolysaccharides below $8000 \mathrm{Da}$ are not detected by the LAL test and can still induce secretion of inflammatory cytokines (11). The only laboratory in Lebanon equipped to perform this test uses the chromogenic LAL endotoxin assay kit and can detect down to $0.01 \mathrm{EU} / \mathrm{mL}$.

In accordance with the decree, new regulations concerning hemodialysis practice were released in order to improve the whole management of dialysis patients. Thus, all patients should undergo dialysis three times per week and each session should last four hours at least. Nephrologists are not allowed to work in more than one

\begin{tabular}{|c|c|}
\hline Chemical contaminant & $\begin{array}{l}\text { Maximum recommended } \\
\text { concentration }(\mathrm{mg} / \mathrm{l}=\mathrm{ppm})\end{array}$ \\
\hline Lead & 0.005 \\
\hline Aluminum & 0.01 \\
\hline Nitrate (as N) & 2 \\
\hline Total chlorine & 0.1 \\
\hline Copper & 0.1 \\
\hline Fluoride & 0.2 \\
\hline Magnesium & $4(0.15 \mathrm{mmol} / \mathrm{L})$ \\
\hline Calcium & $2(0.05 \mathrm{mmol} / \mathrm{L})$ \\
\hline Potassium & $8(0.2 \mathrm{mmol} / \mathrm{L})$ \\
\hline Sodium & $70(3 \mathrm{mmol} / \mathrm{L})$ \\
\hline
\end{tabular}

Table 3 Maximum allowable levels for TDS, Chlorine, Total viable microbial count (TVC) and Endotoxins, to be tested once per month

\begin{tabular}{lc} 
Parameter tested & $\begin{array}{c}\text { Maximum allowable level in } \\
\text { ultrapure water }\end{array}$ \\
\hline TDS & $10 \mathrm{ppm}$ \\
Total Chlorine & $0.1 \mathrm{mg} / \mathrm{I}$ \\
TVC & $0.1 \mathrm{CFU} / \mathrm{mL}$ \\
Endotoxins & $0.03 \mathrm{EU} / \mathrm{mL}$ \\
\hline
\end{tabular}

dialysis facility (each nephrologist is responsible for a maximum of 40 patients). For every four dialysis patients, there needs to be one registered nurse in each shift.

Dialyzer membranes, bloodlines and fistula needles should be FDA (Food and Drug Administration) approved or CE (European Conformity) certified and surfaces should be appropriately chosen accordingly to every patient's body surface. Bicarbonate concentrate should be supplied in a powder form. High-flux synthetic membranes should be used after the implementation of ultrapure water. A separate machine should be used for HBs Ag positive patients. The MoPH will reimburse the blood tests as indicated in Table 4.

\section{Rationale for the new recommendations}

\section{Rationale for the water treatment system}

Water treatment systems are designed to produce dialysis-quality water, but the types of components used can vary significantly according to the local water quality and the contaminants that must be removed (8). RO will remove more than $95 \%$ of chemicals and endotoxins and it should be equipped with online monitors that display TDS to measure its performance. We recommended double reverse osmosis to be placed in series to ensure a better quality of the water especially since, in some regions of Lebanon, the TDS of the municipal drinking water is very high. The other reason for a double RO system is to 


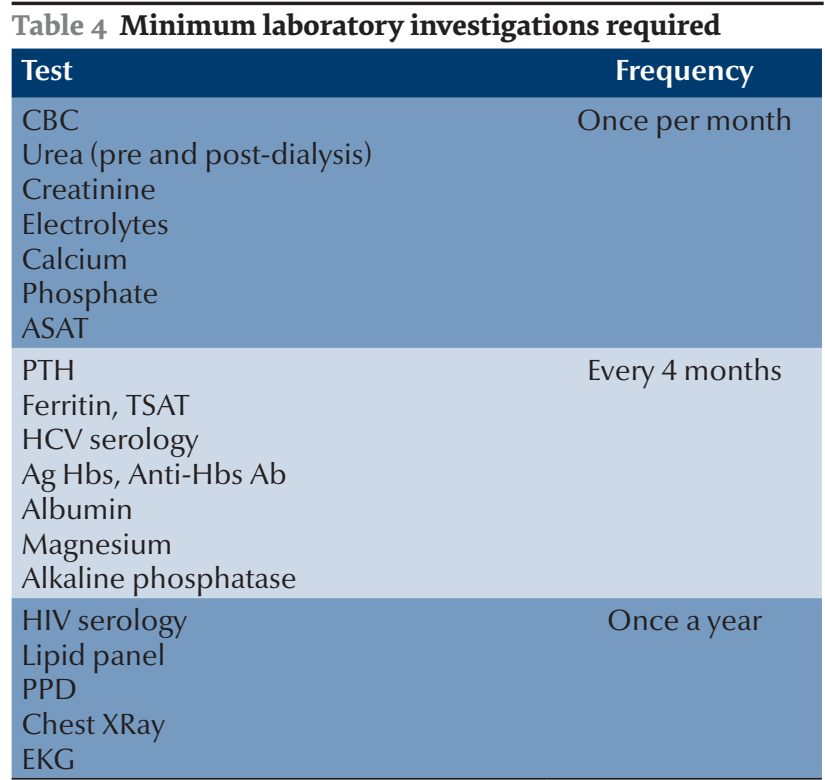

encounter any possible pump failure due to a cut out by the functional pump and prevent inappropriate water quality delivery to the patients.

Endotoxin-retentive filters remove endotoxins and may be configured in a cross-flow mode or dead-end mode. Endotoxin retentive filters should be placed in dialysis water systems at locations downstream of RO and also in the dialysis fluid line as a final barrier (7). Bacteria attach to surfaces and aggregate in a biopolymer matrix to form biofilm. Due to inadequate disinfection protocols, membranes are exposed to persistent bacterial contamination and biofilm is allowed to form and grow (14). Biofilms should be avoided in HD water treatment systems by allowing a continuous flow of water in a loop without multiple branches or dead-end pipes with direct feed system. Storage tanks are not recommended but if used they must have a conical or bowl-shaped base and should drain from the lowest point of the base. An endotoxin-retentive filter should be installed distal to the storage tank (8). All those requirements are essential to reduce to a minimum the endotoxin level and ensure ultrapure water.

\section{Rationale for the need of ultrapure water}

Higher endotoxin levels in dialysis fluid may be related to increased morbidity and increased risk for all-cause mortality among HD patients. Correcting this parameter might improve the response to erythropoietin, the inflammatory markers and the outcome of hemodialysis patients $(3,15,16)$. Ultrapure water use is mandatory when using high-flux membranes. In fact, high-flux membranes, with larger pores than low-flux membranes, allow convection and are prone to the passage of endotoxins from the dialysate to the patient's blood. Endotoxins are lipopolysaccharides with a molecular mass that ranges between 2000 to $20000 \mathrm{Da}$ and thus cross the large pores easily (1,11). In 2002, the European Best Practice Guidelines (named the European Renal Best Practice [ERBP] since 2008) for HD published new recommendations encouraging the use of synthetic high-flux membranes and ultrapure dialysis fluid as a goal for all patients and all modalities to delay long-term complications of HD therapy (17). A large randomized controlled study, the HEMO study, showed a benefit of high-flux membranes on survival when dialysis duration exceeded 3.7 years (18). In the membrane permeability outcome (MPO) study, a significantly higher survival rate for patient subgroups with a serum albumin below $4 \mathrm{~g} / \mathrm{dL}$ and for diabetic patients was observed when they were treated with high- compared with low-flux membranes (19).

Moreover, Kim et al. (20) have shown that patients without residual renal function dialyzed with high-flux membranes had a $60 \%$ less risk of death than those treated with the low-flux In Japan. A large cohort study showed that patients exposed to $\geq 0.1 \mathrm{EU} / \mathrm{mL}$ of endotoxin in dialysis fluid had a $28 \%$ higher risk of all-cause mortality than those exposed to $<0.001 \mathrm{EU} / \mathrm{mL}$ (ultrapure endotoxin target level set by the JSDT for dialysis fluid) (3).

Finally, the reliability of any endotoxin level depends on a right sampling. Prior to sampling, the outlet system (sample port or connector) should be disinfected using $70 \%$ ethanol, with an exposure time of $\geq 30 \mathrm{~s}$. Sample recipients should be sterile and endotoxin-free. The first sample of $\geq 20 \mathrm{~mL}$ should be discarded and a fresh sample should be taken using a new syringe. For ET quantification and bioassay, a sample volume of $5 \mathrm{~mL}$ each will suffice. Samples should be stored at $4^{\circ} \mathrm{C}$ for a maximum of $24 \mathrm{~h}(11)$.

\section{Rationale for the laboratory investigations and haemodialysis schedule}

Regarding the routine blood tests and the three sessions per week, the MoPH followed the latest KDIGO Clinical Practice guidelines for the treatment of anemia and CKDMBD $(21,22)$ and the European Best Practice Guideline (currently ERBP) (23), respectively.

\section{New policy implementation}

\section{Ultrapure water implementation strategy and barriers}

After the decree's release, MoPH organized a meeting to ask for feedback of all concerned parties, nephrologists, hospitals' administration and water systems' providers. Three main concerns were identified: the cost and feasibility of the new water system, the time needed for implementation in the whole country, and the acceptance of the nephrologists of this new responsibility.

Since all the dialysis centres in Lebanon are based in hospitals, the first barrier was the acceptance of the additional cost by the hospitals' union. They found the new system's cost high and the modification of the infrastructure difficult. But after long discussions 
with the engineers it became clear that the new piping can be installed without modifying the building. After calculation of the number of sessions reimbursed for an average centre of 40 patients (Table 5) multiplied by the US\$ 29 increase for each session, the payback period of the US\$100 000 cost of the new water treatment system was estimated to be 6-7 months.

The other issue was that installation of a new water treatment system in all 70 facilities in Lebanon would take time. One year is not enough to establish ultrapure water in all centres knowing that there are only four dialysis providers with good experience in water treatment systems and that piping will be done at the end of the day after patients leave the dialysis facility. Therefore, the first step would be to ensure that all centres have signed the agreements concerning this project and would proceed with its execution in the near future. Second, the deadline of one year previously agreed by the $\mathrm{MoPH}$ would need to be extended for an additional year.

Finally, nephrologists' concerns have been addressed; a meeting between nephrologists, biomedical engineers and dialysis providers was held in June 2015 to spread awareness about the importance of the quality of water used in haemodialysis. This kind of meeting should take place on a more regular basis (probably annually till the whole country is provided with ultrapure water). Nephrologists need to know that the supplier of the water treatment system is responsible for assuring that the water produced meets the maximum allowable chemical contaminant levels required by ISO standards at installation. Beyond this qualification, it becomes the responsibility of the physician in charge of dialysis to monitor the system to ensure that the treatment devices maintain an acceptable level of purity of the water $(8,13)$.

During and after the adoption of the ultrapure water in all Lebanese dialysis facilities, nephrologists must send the results of the endotoxin level and TDS to the MoPH on a monthly basis, and if they are not in the acceptable range, corrective measures should be applied.

\section{Economic evaluation}

\section{The total cost of the new water treatment sys- tem}

The goal of any healthcare delivery system is to improve the value of a treatment while keeping it cost effective. The cost of a total new water treatment system varies between US\$ 60000 and US\$ 100000 whether the disinfection is chemical or thermal respectively. Assuming that some centres would keep their old pre-treatment system that cost on average US\$15000, the additional installation of a double RO and a distribution loop with chemical or heat disinfection will cost only from US\$ 45000 to US\$ 85000 .

The project of aiming to improve the water quality includes an increase in the reimbursement of each dialysis session by US\$29, leading to a total of US\$ 102 per session instead of US\$73 as witnesses in the past (Table 5). The other paying parties (NSSF, Army) joined the $\mathrm{MoPH}$ in this new regulation. This raised the cost of HD treatment on the national level by $\sim$ US $\$ 15000000$ for the year 2015. The annually cost of HD per patient was US\$15 340 before the decree release. After its release, the annually cost per patient for HD reimbursed as a bundled fee by the MoPH, NSSF or Army rose to US\$19 916. This bundled fee takes into account mainly the direct medical and non-medical costs. Direct medical costs include staffing costs, physician fees, costs of dialyzers and tubing, costs associated with radiology, laboratory and medications and capital costs of HD machines.

The direct non-medical costs include the building, the electricity and the water costs. It would be important to add that the annual reimbursed cost for PD per patient varies between US\$14240 and US\$24000 depending on the company providing the bags and the technique (CAPD or APD). Erythropoietin for PD patients is covered also by the MoPH and has been included in the above total amount. Laboratory ( $\geq$ US\$1100 annually) and physician (US\$200 to \$600) fees for PD are not covered by the MoPH.

\begin{tabular}{|c|c|c|c|c|c|c|}
\hline & $\begin{array}{l}\text { Old* } \\
\text { reimbursed } \\
\text { fee per } \\
\text { session }\end{array}$ & $\begin{array}{l}\text { New** } \\
\text { reimbursed } \\
\text { fee per } \\
\text { session }\end{array}$ & $\begin{array}{l}\text { Old total } \\
\text { amount } \\
\text { reimbursed for } \\
40 \text { patients per } \\
\text { facility per year } \\
\text { (6240 sessions) }\end{array}$ & $\begin{array}{l}\text { New total } \\
\text { amount } \\
\text { reimbursed for } \\
40 \text { patients per } \\
\text { facility per year } \\
\text { (6240 sessions) }\end{array}$ & $\begin{array}{l}\text { Old total amount } \\
\text { reimbursed } \\
\text { for the } 3500 \\
\text { patients in the } \\
\text { country per } \\
\text { year (546 000 } \\
\text { sessions) }\end{array}$ & $\begin{array}{l}\text { New total amount } \\
\text { reimbursed for } \\
\text { the } 3500 \text { patients } \\
\text { in the country per } \\
\text { year ( } 546000 \\
\text { sessions) }\end{array}$ \\
\hline $\begin{array}{l}\text { Bundled fee } \\
\text { including medical } \\
\text { and non-medical } \\
\text { costs }\end{array}$ & $\$ 73$ & $\$ 73$ & $\$ 455520$ & $\$ 455520$ & $\$ 39858000$ & $\$ 39858000$ \\
\hline $\begin{array}{l}\text { Added amount } \\
\text { to cover the new } \\
\text { water system }\end{array}$ & $\mathrm{N} / \mathrm{A}$ & $\$ 29$ & $\mathrm{~N} / \mathrm{A}$ & $\$ 180960$ & $\mathrm{~N} / \mathrm{A}$ & $\$ 15834000$ \\
\hline Total & $\$ 73$ & $\$ 102$ & $\$ 455520$ & $\$ 636480$ & $\$ 39858000$ & $\$ 55692000$ \\
\hline
\end{tabular}

*Old means before the decree release and the implementation of ultrapure water.

**New means after ultrapure water implementation. 
Dialysis is known to be cost-effective worldwide. A study done in Japan on the cost-effectiveness of HD according to primary disease found that HD is a costeffective intervention in elderly patients especially in diabetic patients (24). However, the costvaries significantly between high-income and low- and middle-income countries. According to the USRDS 2013 Annual Report, the annual per patient cost of HD in the United States of America is $\sim$ US\$ 89000 per year (12). This cost becomes highly variable when considering low to middle-income countries. It is also variable within one country category (HD cost per patient per year ranged from US\$3424 to US\$ 42 785, and PD from US\$ 7974 to US\$ 47 971) $(4,5,25)$. In all cases the cost of dialysis per year is higher than the gross national product in those low to middle-income countries (25). Lebanon is an upper middle-income country, with a GNI per capita of US\$ 10030 according to the World Bank 2014 (6). However, the estimated dialysis costs in Lebanon (US\$ 19916 per patient per year), even with the higher quality of water, remain lower compared to other upper middle-income countries (e.g., Brazil, Chile, China, Malaysia, South Africa and Turkey) (25).

It is not enough to show that high-quality hemodialysis is less expensive in Lebanon; we need also to assess the cost-effectiveness of taking into account the per capita GNI. In public health, when comparing interventions, the incremental cost-effectiveness ratio (ICER) - i.e. the difference in costs divided by the difference in health effects - is often used (26). Dialysis is a life-sustaining therapy and patients who need it but do not get it will die. With this in mind, ICER of a dialysis treatment is calculated as its cost per quality-adjusted life-year (QALY) gained. Thus, the ICER of haemodialysis in Lebanon would be the ratio of the yearly cost (US\$ 19 916) divided by one year of life gained. In an attempt to compare ICERs between two healthcare systems, the WHO's Choosing Interventions that are Cost-Effective (WHOCHOICE) project suggested using the ratio between cost and per capita GNI, knowing that a ratio $<1$ is highly costeffective and a ratio $<3$ is cost-effective (26). The ratio of cost-effectiveness of haemodialysis with the new water system would be US\$19 916 divided by the Lebanese per capita GNI US\$10 030, and calculated as 1.98 or $\sim 2$. According to this cost-effectiveness threshold, dialysis upgraded with ultrapure water in Lebanon remains costeffective.

\section{Future needs}

One laboratory for endotoxin measurement is not enough for a whole country. More laboratories able to perform the test with a reduced cost need to be involved. Installation of heat disinfection in all facilities must be encouraged since it is the most practical and safest way for disinfection of the loop system with a high performance in preventing biofilms. We need observational studies comparing the era before and after ultrapure water implementation. Variables that should be assessed are mortality, quality of life and haemoglobin levels along with erythropoiesis-stimulating agents (ESAs) and iron doses used. Finally, we need, as a next step, to promote and put regulations for PD utilization in ESRD patients, since it appears to be more cost-effective than HD (assuming that $\mathrm{HD}$ and $\mathrm{PD}$ provide the same survival).

\section{Conclusion}

Providing ultrapure water for haemodialysis is a long process that involves many concerned parties and needs thorough economic assessment. From our experience, implementing ultrapure water for HD in upper middle-income countries, and recommending three sessions per week, is feasible and cost effective. It needs an initial evaluation of the community's needs and acceptance, strict regulations enforced by the country's government, and should be maintained by sustained efforts from nephrologists to keep dialysis water purity at its best level.

\section{Funding: None.}

Competing interests: None declared.

\section{Utilisation de l'eau ultrapure en hémodialyse : vers une qualité supérieure au Liban Résumé}

La communauté de la néphrologie assiste, partout dans le monde, à l'essor de l'utilisation des membranes à haut débit et de l'eau ultrapure dans les unités d'hémodialyse. Dans les pays à revenu faible ou intermédiaire, les données concernant la qualité de l'eau employée dans les unités d'hémodialyse sont insuffisantes. Au Liban, le ministère de la Santé publique a publié un décret préconisant le changement progressif du système de traitement de l'eau utilisée dans les unités d'hémodialyse afin de généraliser l'emploi de l'eau ultrapure dans tous les établissements de dialyse. Le présent article fait état des problèmes de qualité de l'eau auparavant rencontrés au Liban. Il expose aussi les changements de normes récemment mis en œuvre conformément aux recommandations du gouvernement, et en particulier l'adoption des trois séances hebdomadaires obligatoires et de l'eau ultrapure. En outre, il analyse le rapport coût-efficacité de la mise en œuvre de l'eau ultrapure dans un pays à revenu faible/intermédiaire et démontre que son coût est inférieur à celui constaté dans les pays dont le revenu est élevé. Enfin, cet article résume les obstacles rencontrés et suggère une approche pratique visant à maintenir un niveau de qualité de traitement de l'eau aussi haut. 


\section{المياه فائقة النقاوة في غسيل الكلى: خطوة نحو جودة أفضل في لبنان مابيل عون، جهاد مكوك، وليد عَّارّ

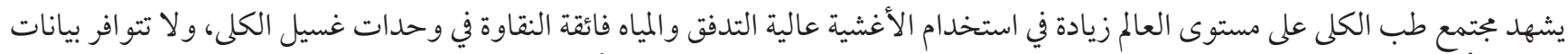

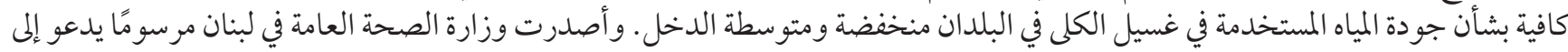

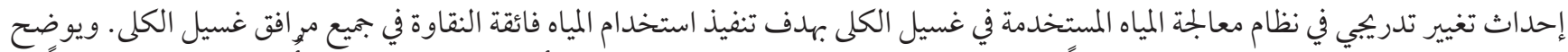

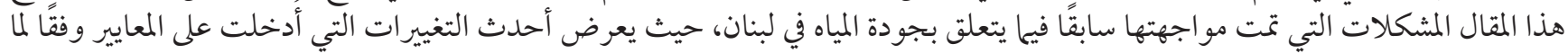

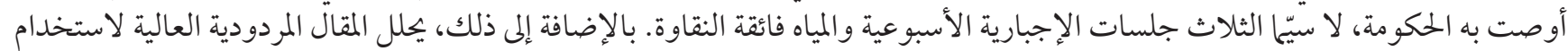

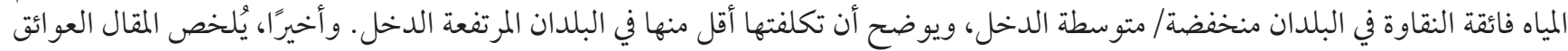

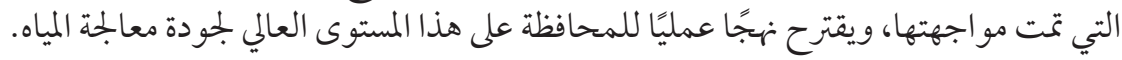

\section{References}

1. Blankestijn PJ, Ledebo I, Canaud B. Hemodiafiltration: clinical evidence and remaining questions. Kidney Int. 2010;77(7):581-7. http://dx.doi.org/10.1038/ki.2009.541

2. Coulliette AD, Arduino MJ. Hemodialysis and Water Quality. Semin Dial. 2013;26(4):427-38. http://dx.doi.org/10.1111/sdi.12113

3. Hasegawa T, Nakai S, Masakane I, Watanabe Y, Iseki K, Tsubakihara Y, et al. Dialysis Fluid Endotoxin Level and Mortality in Maintenance Hemodialysis: A Nationwide Cohort Study. Am J Kidney Dis. 2015;65(6):899-904. http://dx.doi.org/10.1053/j. ajkd.2014.12.009

4. Karopadi A, Mason G, Rettore E, Ronco C. Cost of peritoneal dialysis and haemodialysis across the world. Nephrol Dial Transplant. 2013;28(10):2553-69. http://dx.doi.org/10.1093/ndt/gft214

5. Just PM, de Charro FT, Tschosik EA, Noe LL, Bhattacharyya SK, Riella MC. Reimbursement and economic factors influencing dialysis modality choice around the world. Nephrol Dial Transplant. 2008;23(7):2365-73. http://dx.doi.org/10.1093/ndt/gfm939

6. World Bank. World Development Indicators 2014. Washington: The World Bank Press; 2014.

7. International Organization for Standardization (ISO). ISO 23500: Guidance for the preparation and quality management of fluids for haemodialysis and related therapies. Geneva: ISO; 2014.

8. International Organization for Standardization (ISO). 26722: 2014, Water treatment equipment for hemodialysis applications and related therapies. Geneva: ISO; 2014.

9. International Organization for Standardization (ISO). 13959: 2014, Water for haemodialysis and related therapies, Geneva: ISO; 2014.

10. International Organization for Standardization (ISO). 11663: 2014, Quality of dialysis fluid for haemodialysis and related therapies, Geneva: ISO; 2014.

11. Glorieux G, Neirynck N, Veys N, Vanholder R. Dialysis water and fluid purity: more than endotoxin. Nephrol Dial Transplant. 2012;27(11):4010-21. http://dx.doi.org/10.1093/ndt/gfs306

12. U.S. Renal Data System. USRDS 2013 Annual Data Report: Atlas of Chronic Kidney Disease and End-Stage Renal Disease in the United States. Bethesda (MD): National Institutes of Health, National Institute of Diabetes and Digestive and Kidney Diseases; 2013.

13. Kasparek T, Rodriguez O. What Medical Directors Need to Know about Dialysis Facility Water Management. Clin J Am Soc Nephrol. 2015;10(6):1061-71. http://dx.doi.org/10.2215/CJN.11851214

14. Cappelli G, Ballestri M, Perrone S, Ciuffreda A, Inguaggiato P, Albertazzi A. Biofilms invade nephrology: effects in hemodialysis. Blood Purif. 2000;18(3):224-30. http://dx.doi.org/10.1159/000014421

15. Matsuhashi N, Yoshioka T. Endotoxin-free dialysate improves response to erythropoietin in hemodialysis patients. Nephron. 2002;92(3):601-4. http://dx.doi.org/10.1159/000064087

16. Rahmati MA, Homel P, Hoenich NA, Levin R, Kaysen GA, Levin NW. The role of improved water quality on inflammatory markers in patients undergoing regular dialysis. Int J Artif Organs. 2004;27(8):723-7. http://dx.doi.org/10.1177/039139880402700811

17. Tattersall J, Canaud B, Heimburger O, Pedrini L, Schneditz D, Van Biesen W. High-flux or low-flux dialysis: a position statement following publication of the Membrane Permeability Outcome study. Nephrol Dial Transplant. 2010;25(4):1230-2. http://dx.doi. org/10.1093/ndt/gfp626

18. Cheung AK, Levin NW, Greene T, et al. Effects of high-flux hemodialysis on clinical outcomes: results of the HEMO study. J Am Soc Nephrol. 2003;14(12):3251-63. http://dx.doi.org/10.1097/01.ASN.0000096373.13406.94

19. Locatelli F, Martin-Malo A, Hannedouche T, Loureiro A, Papadimitriou M, Wizemann V, et al. Effect of membrane permeability on survival of hemodialysis patients. J Am Soc Nephrol. 2009;20(3):645-54. http://dx.doi.org/10.1681/ASN.2008060590 
20. Kim HW, Kim S-H, Kim YO, Jin DC, Song HC, Choi EJ, et al. Comparison of the impact of high-flux dialysis on mortality in hemodialysis patients with and without residual renal function. PLoS One. 2014;9(6):e97184. http://dx.doi.org/10.1371/journal. pone.0097184

21. Kidney Disease: Improving Global Outcomes (KDIGO) Anemia Work Group. KDIGO Clinical Practice Guideline for Anemia in Chronic Kidney Disease. Kidney Int Suppl. 2012;2:279-335.

22. Kidney Disease: Improving Global Outcomes (KDIGO) CKD-MBD Work Group. KDIGO Clinical Practice Guideline for the Diagnosis, Evaluation, Prevention and Treatment of Chronic Kidney Disease-Mineral and Bone Disorder (CKD-MBD). Kidney Int Suppl. 2009;113:S1-130.

23. Tattersall J, Martin-Malo A, Pedrini L, Basci A, Canaud B, Fouque D, et al. EBPG guideline on dialysis strategies. Nephrol Dial Transplant. 2007;22 Suppl 2:ii5-21. http://dx.doi.org/10.1093/ndt/gfmo22

24. Takura T, Nakanishi T, Kawanishi H, et al. Cost-Effectiveness of Maintenance Hemodialysis in Japan. Ther Apher Dial. 2015;19(5):441-9.

25. Mushi L, Marschall P, Fleßa S. The cost of dialysis in low and middle-income countries: a systematic review. BMC Health Serv Res. 2015;15(1):506. http://dx.doi.org/10.1186/s12913-015-1166-8</jrn>

26. World Health Organization. Choosing interventions that are cost-effective [Internet]. Geneva: World Health Organization; 2014. 